\title{
High-Dose Vitamin D Supplementation Does Not Prevent Allergic Sensitization of Infants
}

Jenni Rosendahl, MD, PhD ${ }^{1,2}$, Anna S. Pelkonen, MD, PhD ${ }^{2,3}$, Otto Helve, MD, PhD ${ }^{1,2}$, Helena Hauta-alus, MSc ${ }^{1,2}$, Elisa Holmlund-Suila, MD, $\mathrm{PhD}^{1,2}$, Saara Valkama, $\mathrm{MD}^{1,2}$, Maria Enlund-Cerullo, MD ${ }^{1,2}$, Heli Viljakainen, $\mathrm{PhD}^{4,5}$, Timo Hytinantti, MD, $\mathrm{PhD}^{1,2}$, Outi Mäkitie, MD, $\mathrm{PhD}^{1,2,4}$, Sture Andersson, MD, PhD ${ }^{1,2}$, and Mika J. Mäkelä, MD, $\mathrm{PhD}^{2,3}$

Objective To investigate the effect of vitamin D supplementation dose on allergic sensitization and allergic diseases in infants, and to evaluate whether vitamin D status in pregnancy and at birth are associated with infant allergy outcomes.

Study design Altogether, 975 infants participated in a randomized, controlled trial of daily vitamin $D$ supplementation of $10 \mu \mathrm{g}(400 \mathrm{IU})$ or $30 \mu \mathrm{g}(1200 \mathrm{IU})$ from the age of 2 weeks. At 12 months of age, food and aeroallergen IgE antibodies were measured, and the occurrence of allergic diseases and wheezing were evaluated.

Results We found no differences between the vitamin D supplementation groups in food (OR, 0.98; $95 \% \mathrm{Cl}, 0.66$ 1.46) or aeroallergen sensitization at 12 months (OR, 0.76; $95 \% \mathrm{Cl}, 0.34-1.71)$. Allergic diseases or wheezing did not differ between groups, except for milk allergy which occurred more often in infants administered $30 \mu \mathrm{g}$ vitamin $\mathrm{D}$ compared with the $10 \mu \mathrm{g}$ dose (OR, 2.23; 95\% Cl, 1.00-4.96). Infants with high cord blood 25-hydroxyvitamin D $(\geq 100 \mathrm{nmol} / \mathrm{L})$ had a higher risk of food allergen sensitization compared with those with lower $25(\mathrm{OH}) \mathrm{D}$ concentration (75-99.9 nmol/L; OR, 2.00; 95\% Cl, 1.19-3.39).

Conclusions High-dose vitamin D supplementation did not prevent allergic sensitization, allergic diseases, or wheezing during the first year of life. In contrast, we observed an increased risk of milk allergy in infants randomized to higher vitamin D supplementation, and an increased risk of allergic sensitization in infants with high cord blood vitamin D status, indicating a possible adverse effect of high concentrations of vitamin D. (J Pediatr 2019; $\mathbf{\square}: 1-7)$.

bservational studies demonstrate a link between vitamin D status at birth and the development of allergic diseases. The results are, however, inconsistent. In a Taiwanese birth cohort, maternal vitamin D status was inversely related to allergic sensitization and atopic diseases in the offspring, whereas another study reported positive association of maternal and cord blood 25-hydroxyvitamin $(25(\mathrm{OH}) \mathrm{D})$ levels with children's risk for food allergy and allergic sensitization during the first 2 years of life. ${ }^{1,2}$ A longitudinal follow-up study of children from birth to age 5 years found persistent vitamin D deficiency in childhood to be associated with eosinophilia and allergic sensitization.

Similarly, some studies have reported vitamin D deficiency during pregnancy or in early childhood to be a risk factor for wheezing and later development of asthma, ${ }^{4,5}$ whereas others have found no association. ${ }^{6}$ Three randomized, controlled trials on vitamin D supplementation during pregnancy in prevention of allergic diseases and wheezing have been conducted. ${ }^{7-10}$ One study examined the effect of maternal vitamin D supplementation during lactation on infantile allergic disorders, but no largescale postnatal randomized trials exist. ${ }^{11}$

The Vitamin D Intervention in Infants (VIDI) study was a randomized controlled 24-month trial of daily $10 \mu \mathrm{g}$ or $30 \mu \mathrm{g}$ vitamin D supplementation administered to healthy infants that evaluated the effect of vitamin D supplementation on bone health and infections. ${ }^{12}$ The aim of the present study was, as a secondary analysis, to investigate the effect of the 2 different vitamin $\mathrm{D}$ supplemental doses on early allergic sensitization and allergy-related clinical outcomes, physician-diagnosed allergic diseases, allergy symptoms, and wheezing, during the first year of life.

\section{Methods}

A total of 987 healthy infants, born in Kätilöopisto Helsinki Maternity Hospital, Finland, were randomized to receive daily vitamin $\mathrm{D}_{3}$ supplementation of $10 \mu \mathrm{g}$

From the ${ }^{1}$ Children's Hospital, Pediatric Research Center, University of Helsinki, ${ }^{2}$ Helsinki University Hospital, ${ }^{3}$ Department of Allergy, University of Helsinki, ${ }^{4}$ Folkhälsan Research Center, and the ${ }^{5}$ Department of Food and Environmental Sciences, University of Helsinki, Helsinki, Finland

Supported by the Foundation for Pediatric Research, Finska Läkaresällskapet, the Finnish Medical Foundation, Governmental Subsidy for Clinical Research, the Päivikki and Sakari Sohlberg Foundation, Stiftelsen Dorothea Olivia, Karl Walter och Jarl Walter Perkléns Dorothea Olivia, Karl Walter och Jarl Walter Perklén
minne, the Academy of Finland, the Sigrid Jusélius Foundation, the Folkhälsan Research Foundation, the Novo Nordisk Foundation, the Orion Research Foundation, Barncancerfonden, and Allergy Research Foundation. The funders had no role in the design and conduct of the study; collection, analysis, or interpretation of the data; preparation, review, or approval of the manuscript; data; preparation, review, or approval of the manuscrip
and the decision to submit the manuscript for publication. The authors declare no conflicts of interest.

0022-3476/\$ - see front matter. @ 2019 Elsevier Inc. All rights reserved. https://doi.org/10.1016/j.jpeds.2019.02.021 
(400 IU) or $30 \mu \mathrm{g}$ (1200 IU) from 2 weeks to 24 months of age. ${ }^{12}$ Mothers were of northern European ethnicity without regular medication and with a singleton pregnancy. Infants included in the study were born at term $\left(37^{0 / 7}\right.$ to $42^{0 / 7}$ weeks of gestation) with a birth weight appropriate for gestational age (birth weight SDS between -2.0 and +2.0 ). Those requiring intravenous glucose, antibiotics, nasal continuous positive airway pressure for $>1$ day, phototherapy for $>3$ days, or nasogastric tube feeding for $>1$ day, and with seizures were excluded. Study recruitment occurred between January 2013 and June 2014. We obtained written informed consent from the parents. The study was conducted in accordance with the Declaration of Helsinki, and the Research Ethics Committee of the Hospital District of Helsinki and Uusimaa provided ethical approval (107/13/03/03/2012). The project protocol is registered on ClinicalTrials.gov (NCT01723852) and has been reported previously. ${ }^{12,13}$

Randomization to the 2 vitamin D supplementation groups was performed in blocks of 50 by a pharmacist at Helsinki University Hospital Pharmacy. Study preparations, identical in appearance, contained vitamin $\mathrm{D}_{3}$ dissolved in medium-chain triglyceride oil (Orion Pharmaceuticals, Espoo, Finland) and were administered orally with 5 drops for both groups. The use of other vitamin D supplements was not allowed during the study. The study was double blinded, with participants and investigators masked to group assignment. Compliance with the vitamin D supplementation was assessed from study diaries in which the parents prospectively recorded dosing of the supplement.

\section{Data Collection}

Family demographics were obtained from hospital records and structured questionnaires during follow-up. Pregnancy serum samples were collected at 11 weeks of gestation on average during routine follow-up visits at prenatal clinics and stored in the Finnish Maternity Cohort serum bank maintained by the National Institute for Health and Welfare. We measured the $25(\mathrm{OH}) \mathrm{D}$ concentration from pregnancy serum samples, cord blood, and at 12 months with a fully automated immunoassay (IDS-iSYS, Immunodiagnostic System Ltd., Bolton, UK). ${ }^{12}$ At 12 months, we measured specific IgE antibodies toward food allergens (cow's milk, egg white, wheat, cod, peanut, soy) and toward aeroallergens (birch, mugwort, timothy, horse, cat, dog, Dermatophagoides pteronyssinus, and Cladosporium herbarum) with ImmunoCAP (Phadia, Uppsala, Sweden) at the Laboratory of Helsinki University Hospital. Allergic sensitization to food or aeroallergens was defined as a specific IgE concentration of $\geq 0.35 \mathrm{kU} / \mathrm{L}$.

At 12 months, parents completed structured allergy questionnaires based on a modified International Study of Asthma and Allergies in Childhood questionnaire that included questions on occurrence of physician-diagnosed food allergy ever (cow's milk, wheat, or any food), atopic eczema, or asthma, and allergy symptoms in the child. ${ }^{14} \mathrm{Al}-$ lergy symptoms including wheezing or breathing difficulty, persistent cough, and itchy rash were queried. Wheezing or breathing difficulty was defined as a positive answer to the question, "Has your child ever had wheezing or difficulty in breathing in the preceding 12 months?" Persistent cough was defined as a positive answer to the question, "Has your child had persistent coughing for at least 6 weeks in the preceding 12 months?" Itchy rash was defined as a positive answer to the question, "Has your child had dry, red or itchy skin requiring regular care in the preceding 12 months?"

The number of hospitalizations owing to bronchiolitis or wheezing during the first 12 months was calculated from study diaries in which parents recorded all their child's infections including data on infection type, symptoms, medication, and possible hospitalization during the vitamin D intervention trial. $^{12}$

At 12 months, the dietary intake of vitamin D was determined from a 3-day food record administered by the parents or daycare personnel. Nutrient intakes were processed with AivoDiet software (Aivo Oy Finland, Turku, Finland), which used Fineli, the National Food Composition Database maintained by the National Institute for Health and Welfare, Finland. The calculated total vitamin D intake did not include intake from breast milk. ${ }^{12}$

\section{Statistical Analyses}

Normality of the continuous variables was determined by visual inspection and with the Kolmogorov-Smirnov test of normality. For group comparisons, independent samples $t$ test or Mann-Whitney $U$ test were used in case of continuous variables and the Pearson $\chi^{2}$ or Fisher exact test in case of categorical variables. To evaluate the effect of vitamin D supplementation group on food or aeroallergen sensitization and clinical allergy outcomes, logistic regression was applied, with adjustment for potential confounders based on the associations observed in the present study. Similarly, logistic regression was used to evaluate the effect of pregnancy, cord blood, and the $25(\mathrm{OH}) \mathrm{D}$ concentration at 12 months on food allergen sensitization. All analyses were performed by intention-to-treat principle using SPSS software (IBM SPSS Statistics for Windows, version 22; IBM, Armonk, New York).

\section{Results}

\section{Characteristics}

A total of 975 infants fulfilled the trial inclusion criteria; 489 were randomized to $10 \mu \mathrm{g}$ and 486 to $30 \mu \mathrm{g}$ daily vitamin D supplementation. Study enrollment, allocation, and followup is presented (Figure; available at www.jpeds.com).

At 12 months, a total of 865 infants $(91.5 \%)$ attended the follow-up visit. Parental history of allergic diseases or other baseline characteristics did not differ between intervention groups (Table I). Breastfeeding was continued for $>6$ months for $78.9 \%$ of the infants, with a mean duration of 10.7 months. Pregnancy or baseline cord blood 25(OH) $\mathrm{D}$ concentrations did not differ between the intervention groups (Table I). In pregnancy and at birth, $96.5 \%$ of the mothers and $95.7 \%$ of the infants, respectively, were 
Table I. Characteristics of the study participants randomized to 10 or $30 \mu \mathrm{g}$ vitamin D supplementation

\begin{tabular}{|c|c|c|}
\hline Characteristics & $\begin{array}{l}\text { Vitamin D } \\
10 \mu \mathrm{g}\end{array}$ & $\begin{array}{l}\text { Vitamin D } \\
30 \mu \mathrm{g}\end{array}$ \\
\hline Child & 489/975 (50) & 486/975 (50) \\
\hline Girls & 242/489 (50) & $243 / 486(50)$ \\
\hline Boys & $247 / 489(50)$ & $243 / 486(50)$ \\
\hline Birth weight, $\mathrm{g}^{*}$ & $3514 \pm 379$ & $3565 \pm 410$ \\
\hline Birth length, cm & $50.3 \pm 2$ & $50.4 \pm 2$ \\
\hline \multicolumn{3}{|l|}{ Season of birth } \\
\hline Winter & $100 / 489(20)$ & 89/486 (18) \\
\hline Spring & $197 / 489(40)$ & 203/486 (42) \\
\hline Summer & $108 / 489(22)$ & 109/486 (22) \\
\hline Autumn & $84 / 489(17)$ & $85 / 486(17)$ \\
\hline Siblings & 153/444 (34) & 178/448 (40) \\
\hline Breastfeeding $>6$ months & $330 / 428(77)$ & $344 / 426(81)$ \\
\hline Daycare attendance at 12 months & 15/435 (3) & 23/431 (5) \\
\hline Pets & 131/380 (35) & 129/377 (34) \\
\hline \multicolumn{3}{|l|}{$\begin{array}{l}\text { Baseline } 25(\mathrm{OH}) \mathrm{D} \\
\quad \text { concentration, nmol// }{ }^{\dagger}\end{array}$} \\
\hline Pregnancy & $82.0 \pm 22.1$ & $81.6 \pm 18.0$ \\
\hline Cord blood & $81.7(28)$ & $81.3(24)$ \\
\hline \multicolumn{3}{|l|}{ Mother } \\
\hline \multicolumn{3}{|l|}{ History of allergic disease } \\
\hline Asthma & 28/403 (7) & $30 / 411(7)$ \\
\hline Allergic rhinitis & 128/403 (32) & 123/411 (30) \\
\hline Atopic eczema & $74 / 403(18)$ & $61 / 411(15)$ \\
\hline Food allergy & 70/403 (17) & $59 / 411(14)$ \\
\hline Smoking & 17/427 (4) & 15/442 (3) \\
\hline \multicolumn{3}{|l|}{ Educational level $^{\ddagger}$} \\
\hline Low & $119 / 437(27)$ & $107 / 446(24)$ \\
\hline High & $318 / 437$ (73) & $339 / 446(76)$ \\
\hline $\begin{array}{l}\text { Use of vitamin D supplements } \\
\text { in pregnancy }\end{array}$ & $407 / 430$ (95) & $406 / 433(94)$ \\
\hline \multicolumn{3}{|l|}{ Father } \\
\hline \multicolumn{3}{|l|}{ History of allergic disease } \\
\hline Asthma & $27 / 403(7)$ & 38/411 (9) \\
\hline Allergic rhinitis & 136/403 (34) & 158/411 (39) \\
\hline Atopic eczema & $47 / 403(12)$ & 44/411 (11) \\
\hline Food allergy & $56 / 403(14)$ & $62 / 411(15)$ \\
\hline Smoking & $60 / 419(14)$ & $64 / 425$ (15) \\
\hline \multicolumn{3}{|l|}{ Educational level $^{\ddagger}$} \\
\hline Low & 164/434 (38) & $164 / 436(38)$ \\
\hline High & 270/434 (62) & $272 / 436(62)$ \\
\hline
\end{tabular}

Values are $\mathrm{n} / \mathrm{N}(\%)$ or mean $\pm \mathrm{SD}$.

${ }^{*}$ Statistically significant difference between groups $(P=.042)$.

tn $=809$ for pregnancy $25(\mathrm{OH}) \mathrm{D} ; \mathrm{n}=955$ for cord blood $25(\mathrm{OH}) \mathrm{D}$.

łLow is defined as less than a bachelor's degree and high as at least a bachelor's degree.

vitamin $\mathrm{D}$ sufficient, defined as $25(\mathrm{OH}) \mathrm{D} \geq 50 \mathrm{nmol} / \mathrm{L}$. At 12 months, the mean $25(\mathrm{OH}) \mathrm{D}$ concentration was significantly higher in the $30 \mu \mathrm{g}$ vitamin $\mathrm{D}$ group compared with the $10 \mu \mathrm{g}$ group $(115.0 \mathrm{nmol} / \mathrm{L}$ vs $82.7 \mathrm{nmol} / \mathrm{L} ; P<.001)$. At 12 months, the mean daily vitamin $\mathrm{D}$ intake from food was $6.2(\mathrm{SD}, 3.7) \mu \mathrm{g}$ with no differences between the groups $(P=.322)$.

\section{Effect of Vitamin D Supplementation on IgE Sensitization}

At 12 months of age, we obtained serum samples for measurement of specific IgE antibodies from 723 of the 975 children $(74.2 \%$; ie, from $83.6 \%$ of those attending the 12-month follow-up visit). IgE sensitization to food allergens was observed in 114 of 723 children $(15.8 \%)$ and to aeroallergens in 25 of 719 children (3.5\%). Food IgE sensi- tization was most common to egg white (10.4\%) and cow's milk (5.8\%; Table II) and occurred more often in children born to parents with a history of allergic disease (OR, 1.16; 95\% CI, 1.02-1.33) and in those attending daycare at 12 months (OR, 2.45; 95\% CI, 1.13-5.29). Season of birth, duration of breastfeeding, existence of older siblings, or parental smoking did not affect the risk of allergic sensitization at 12 months. We found no difference in specific IgE sensitization between the intervention groups (Table II). The results did not change after adjustment for potential confounding factors (ie, parental history of allergy or daycare attendance). We also repeated the analyses using a higher cut-off for food IgE sensitization (ie, food $\operatorname{IgE}$ of $>0.5$ and $5.0 \mathrm{kU} / \mathrm{L}$ ), but the findings remained unaltered showing no differences in IgE sensitization between the groups. The distribution of cow's milk IgE did not differ between groups: the mean cow's milk IgE was 0.94 (SD 2.3) $\mathrm{kU} / \mathrm{L}$ in the $10 \mu \mathrm{g}$ vitamin $\mathrm{D}$ group and 1.35 (SD 4.2) $\mathrm{kU} / \mathrm{L}$ in the $30 \mu \mathrm{g}$ group $(P=.866)$. No statistically significant differences were seen in cow's milk IgE sensitization stratified by birth season $(P=.872)$.

\section{Effect of Vitamin D Supplementation on Allergic Diseases and Allergy Symptoms}

Data on physician-diagnosed allergic diseases and allergy symptoms reported by parents were obtained from 770 of 975 children (79\%) at 12 months. We found no difference between the intervention groups in physician-diagnosed wheat allergy, any food allergy, atopic eczema, or asthma (Table III). Physician-diagnosed cow's milk allergy was reported more often in the group receiving $30 \mu \mathrm{g}$ vitamin D supplementation compared with the $10 \mu \mathrm{g}$ vitamin D group $(20 / 387$ [5.2\%] vs 9/377 [2.4\%]; $P=.044$; Table III). The findings were unaltered after adjustment for potential confounding factors, that is, a parental history of allergic disease and the duration of breastfeeding. Of infants with reported cow's milk allergy $(n=29), \operatorname{IgE}$ sensitization to cow's milk was observed in only 4 of 25 children (16\%; 4 missing blood samples).

Wheezing or breathing difficulty during the first year of life was reported in 76 of 763 of the cohort (10.1\%) with no difference between the intervention groups (Table III). Likewise, the number of children hospitalized for bronchiolitis or wheezing was similar in both groups (Table III). At 12 months, physician-diagnosed asthma was rare, with only 1 child reported to have an asthma diagnosis.

\section{Allergic Sensitization according to Vitamin D Status}

We observed no correlation between pregnancy or cord blood 25(OH)D and specific food or aeroallergens IgE concentrations at 12 months $(P>.1$ for all). However, when dividing cord blood 25(OH)D concentration in subgroups $<75 \mathrm{nmol} / \mathrm{L}(\mathrm{n}=295), 75.0-99.9 \mathrm{nmol} / \mathrm{L}(\mathrm{n}=286)$, and $\geq 100 \mathrm{nmol} / \mathrm{L}(\mathrm{n}=126)$, the risk for $\mathrm{IgE}$ sensitization to food allergens was higher in infants with cord blood $25(\mathrm{OH}) \mathrm{D}$ concentration was $>100 \mathrm{nmol} / \mathrm{L}$ compared with 
Table II. Allergic sensitization to food or aeroallergens at 12 months in infants randomized to $10 \mu \mathrm{g}$ or $30 \mu \mathrm{g}$ vitamin D supplementation

\begin{tabular}{|c|c|c|c|c|c|}
\hline Allergic sensitizations at 12 months & All & Vitamin D $10 \mu \mathrm{g}$ & Vitamin D $30 \mu \mathrm{g}$ & $P$ value* & OR $(95 \% \text { Cl })^{\dagger}$ \\
\hline Food IgE sensitization & $114 / 723$ (15.8) & $57 / 358$ (15.9) & $57 / 365$ (15.6) & .910 & $0.98(0.66-1.46)$ \\
\hline Cow's milk & $42 / 720(5.8)$ & $21 / 358(5.9)$ & $21 / 362(5.8)$ & .974 & \\
\hline Wheat & $17 / 720(2.4)$ & $10 / 358(2.8)$ & $7 / 362(1.9)$ & .448 & \\
\hline Egg white & $75 / 720(10.4)$ & 40/358 (11.2) & $35 / 362(9.7)$ & .509 & \\
\hline Cod & $3 / 720(0.4)$ & 2/358 (0.6) & $1 / 362(0.3)$ & .622 & \\
\hline Soybean & $8 / 720(1.1)$ & 6/358 (1.7) & 2/362 (0.6) & .175 & \\
\hline Peanut & $23 / 720(3.2)$ & $16 / 358(4.5)$ & $7 / 362(1.5)$ & .053 & \\
\hline Aeroallergen IgE sensitization & 25/719 (3.5) & 14/356 (3.9) & $11 / 363(3.0)$ & .509 & $0.76(0.34-1.71)$ \\
\hline Birch & 10/718 (1.4) & $6 / 356(1.7)$ & $4 / 362(1.1)$ & .543 & \\
\hline Mugwort & $0 / 718$ & 0 & 0 & $\ddagger$ & \\
\hline Timothy & $3 / 718(0.4)$ & $3 / 356(0.8)$ & $0 / 362(0)$ & .121 & \\
\hline Dog & 13/718 (1.8) & $7 / 356(2.0)$ & $6 / 362(1.7)$ & .765 & \\
\hline Cat & 10/718 (1.4) & $5 / 356(1.4)$ & $5 / 362(1.4)$ & 0.979 & \\
\hline Horse & 2/716 (0.3) & 2/355 (0.6) & $0 / 361(0)$ & .245 & \\
\hline Dermatophagoides pteronyssinus & $1 / 718(0.1)$ & $1 / 356(0.3)$ & $0 / 362(0)$ & .496 & \\
\hline Cladosporium herbarum & $1 / 718(0.1)$ & $1 / 356(0.3)$ & $0 / 362(0)$ & .496 & \\
\hline
\end{tabular}

Allergic sensitization defined as serum food or aeroallergen $\lg \mathrm{E}$ of $\geq 0.35 \mathrm{kU} / \mathrm{L}$.Total food and aeroallergen $\lg \mathrm{E}$ sensitization is presented in bold.

Values are $\mathrm{n} / \mathrm{N}(\%)$.

${ }^{*} P$ values are from a Pearson $\chi^{2}$ or Fisher exact test when the cell count is $\leq 5$.

†OR from logistic regression with $95 \% \mathrm{Cl}$.

$\ddagger$ Not applicable owing to the small number of subjects.

those with a concentration between 75.0 and $99.9 \mathrm{nmol} / \mathrm{L}$ (OR, 2.00; 95\% CI, 1.19-3.39; Table IV). The finding persisted after adjustment for potential confounding factors, including adjustment for the intervention group (Table IV). No similar effect was seen when analyzed by pregnancy $25(\mathrm{OH}) \mathrm{D}$ concentration (Table IV). When analyzed according to $25(\mathrm{OH}) \mathrm{D}$ concentration measured at 12 months divided in the same subgroups $(<75.0,75.0$ 99.9, $\geq 100 \mathrm{nmol} / \mathrm{L}$ ), we found no difference in allergic sensitization to food allergens in the unadjusted model (Table IV). However, in the adjusted analysis, the risk for food IgE sensitization was higher in infants with a $25(\mathrm{OH})$ $\mathrm{D}$ concentration at 12 month of $>100 \mathrm{nmol} / \mathrm{L}$ compared with those with a concentration between 75.0 and $99.9 \mathrm{nmol} / \mathrm{L}$. Proportions of aeroallergen-positive infants did not differ according to maternal, cord blood, or $25(\mathrm{OH}) \mathrm{D}$ concentration at 12 months (data not shown).

\section{Discussion}

In this randomized, controlled trial comparing daily vitamin $\mathrm{D}$ supplementation of $10 \mu \mathrm{g}$ and $30 \mu \mathrm{g}$ in infancy, we observed no differences in allergic sensitization between the groups at 12 months of age. Physician-diagnosed allergic diseases and occurrence of wheezing were similar in both intervention groups. Exception was for cow's milk allergy, which was reported more often in infants administered $30 \mu \mathrm{g}$ vitamin $\mathrm{D}$ daily compared with the $10 \mu \mathrm{g}$ dose. In addition, we observed that infants with high cord blood $25(\mathrm{OH}) \mathrm{D}$ levels before the intervention had an increased risk for allergic sensitization compared with those with a lower vitamin $\mathrm{D}$ status. The main observation of our study is that increasing vitamin $\mathrm{D}$ status by higher vitamin $\mathrm{D}$ supplementation in infancy does not protect from allergic sensitization, allergic diseases, or wheezing during the first year of life.

Table III. Parental report of physician-diagnosed allergic disease and allergy symptoms at 12 months in infants randomized to 10 or $30 \mu \mathrm{g}$ vitamin D supplementation

\begin{tabular}{|c|c|c|c|c|c|}
\hline Allergic disease or symptoms & All & Vitamin D $10 \mu \mathrm{g}$ & Vitamin D $30 \mu \mathrm{g}$ & $P$ value* & OR $(95 \% \mathrm{CI})^{\dagger}$ \\
\hline \multicolumn{6}{|l|}{ Physician-diagnosed allergic disease } \\
\hline Cow's milk allergy & 29/764 (3.8) & 9/377 (2.4) & 20/387 (5.2) & .044 & $2.23(1.00-4.96)$ \\
\hline Wheat allergy & 11/762 (1.4) & $5 / 377(1.3)$ & 6/385 (1.6) & .788 & $1.18(0.36-3.89)$ \\
\hline Any food allergy & $47 / 770(6.1)$ & 20/382 (5.2) & 27/388 (7.0) & .318 & $1.35(0.75-2.46)$ \\
\hline Atopic eczema & 128/769 (16.6) & 72/381 (18.9) & 56/388 (14.4) & 097 & $0.72(0.49-1.01)$ \\
\hline Asthma & $1 / 765(0.1)$ & $1 / 378(0.3)$ & 0/387 (0) & .494 & \\
\hline \multicolumn{6}{|l|}{ Allergy symptoms } \\
\hline Wheezing or breathing difficulty & 76/763 (10.0) & $39 / 380(10.3)$ & 37/383 (9.7) & .781 & $0.94(0.58-1.50)$ \\
\hline Hospitalization owing to bronchiolitis or wheezing & 25/901 (2.8) & $14 / 451(3.1)$ & $11 / 450(2.4)$ & .547 & $0.78(0.35-1.74)$ \\
\hline Persistent cough & $46 / 756(6.1)$ & 20/377 (5.3) & 26/379 (6.9) & .371 & $1.32(0.72-2.40)$ \\
\hline Itchy rash & 126/765 (16.5) & $72 / 380(18.9)$ & $54 / 385(16.5)$ & .067 & $0.70(0.48-1.03)$ \\
\hline
\end{tabular}

Values are $\mathrm{n} / \mathrm{N}(\%)$ unless otherwise indicated.

${ }^{\star} P$ values from Pearson $\chi^{2}$ or Fisher exact test when the cell count is $\leq 5$

†OR from logistic regression with $95 \% \mathrm{Cl}$.

$\ddagger$ Not applicable owing to small the number of subjects. 
Table IV. Allergic sensitization to food allergens at 12 months by $25(\mathrm{OH}) \mathrm{D}$ concentration in pregnancy, cord blood and at 12 months

\begin{tabular}{|c|c|c|c|c|c|}
\hline \multirow[b]{2}{*}{ 25(OH)Ds (nmol/L) } & \multicolumn{5}{|c|}{ Food IgE sensitization ( $\geq 0.35 \mathrm{kU} / \mathrm{L}$ ) } \\
\hline & $\mathrm{n} / \mathrm{N}(\%)$ & Unadjusted OR $(95 \% \mathrm{Cl})^{\star}$ & $P$ value & Adjusted OR $(95 \% \mathrm{Cl})^{\dagger}$ & $P$ value \\
\hline \multicolumn{6}{|l|}{ Pregnancy } \\
\hline$<75.0$ & $38 / 224(17.9)$ & $1.28(0.79-2.08)$ & .313 & $1.40(0.83-2.35)$ & .202 \\
\hline $75.0-99.9$ & 40/291 (13.7) & Reference & & Reference & \\
\hline$\geq 100$ & $20 / 99$ (20.2) & $1.59(0.88-2.88)$ & .126 & $1.47(0.76-2.89)$ & .244 \\
\hline \multicolumn{6}{|l|}{ Cord blood } \\
\hline$<75.0$ & $43 / 295(14.6)$ & $1.05(0.66-1.67)$ & .839 & $1.11(0.67-1.85)$ & .689 \\
\hline $75.0-99.9$ & $40 / 286(14.0)$ & Reference & & Reference & \\
\hline$\geq 100$ & $31 / 126(24.6)$ & $2.00(1.19-3.39)$ & .009 & $2.18(1.25-3.80)$ & .006 \\
\hline \multicolumn{6}{|l|}{12 months } \\
\hline$<75.0$ & $26 / 149$ (17.4) & $1.32(0.76-2.30)$ & .331 & $1.82(0.96-3.47)$ & .069 \\
\hline $75.0-99.9$ & $34 / 246(13.8)$ & Reference & & Reference & \\
\hline$\geq 100$ & $54 / 325(16.6)$ & $1.24(0.78-1.98)$ & .360 & $2.10(1.18-3.71)$ & .011 \\
\hline
\end{tabular}

*OR from logistic regression with $95 \% \mathrm{Cl}$.

†Adjusted for vitamin D supplementation group, sex, parental allergy history, and attendance in daycare at 12 months of age.

This study examined the effects of postnatal vitamin D supplementation on allergic diseases in a randomized, controlled setting. Prenatal vitamin D supplementation studies show mixed results. Vitamin D supplementation, administered daily or in a single dose during the third trimester of pregnancy, did not decrease the risk of allergic diseases in the first 3 years of life. ${ }^{7}$ Two randomized trials examined high-dose $(70 \mu \mathrm{g} / \mathrm{d}$ and $110 \mu \mathrm{g} / \mathrm{d})$ vitamin D supplementation regimens compared with a standard dose $(10 \mu \mathrm{g} / \mathrm{d})$ during pregnancy on the risk of recurrent wheezing, asthma, or eczema in the offspring at 3 years of age. ${ }^{8,9}$ Both studies failed to report a statistically significant decrease in the risk of asthma/wheeze with higher prenatal vitamin D supplementation compared with the standard dose. Subsequently, the 2 research groups performed a combined analysis of these trials, which showed that risk of asthma/recurrent wheeze was in fact decreased by $26 \%$ in the offspring. ${ }^{15}$

We found no effect of postnatal vitamin D supplementation on the risk of wheezing at 12 months. It has been suggested that vitamin $\mathrm{D}$ has a role in fetal lung development, and vitamin D deficiency alters normal lung function and structure. ${ }^{16,17}$ Our mothers and infants were, however, mostly vitamin D sufficient during pregnancy and at birth, and during the intervention the $25(\mathrm{OH}) \mathrm{D}$ concentration increased to relatively high levels in the $30 \mu \mathrm{g}$ vitamin $\mathrm{D}$ group. Our results indicate that, in already vitamin D-sufficient infants, there is no advantage of higher vitamin D supplementation against wheezing in the early postnatal period. This finding is supported by our initial finding of vitamin D supplementation not decreasing the incidence of infections during the first 2 years of life, because early childhood wheezing is often related to respiratory infections. ${ }^{12}$

Unexpectedly, the occurrence of cow's milk allergy was more frequent in infants supplemented with $30 \mu \mathrm{g}$ of vitamin $\mathrm{D}$ compared with the $10 \mu \mathrm{g}$ dose. The association of vitamin D supplementation in infancy and an increased risk of allergic conditions have also been reported by others. In a
Finnish population-based study, high-dose vitamin D supplementation in infancy was associated with an increased risk of atopy, allergic rhinitis, and asthma in adulthood. ${ }^{18}$ Similarly, in a Japanese study, short-term vitamin D supplementation of lactating mothers of breast-fed infants with facial eczema did not decrease the severity of infantile eczema, but instead increased the risk of later food allergy. ${ }^{11}$ Furthermore, Weisse et al reported that maternal and cord blood 25(OH)D levels were positively associated with children's risk for food allergy and food allergen sensitization during the first 2 years of life. ${ }^{2}$

The risk of IgE sensitization to food allergens at 12 months of age differed according to cord blood vitamin D status. We observed that infants with cord blood $25(\mathrm{OH}) \mathrm{D}$ concentrations in the highest range $(>100 \mathrm{nmol} / \mathrm{L})$ had increased the odds of food IgE sensitization at 12 months. Previously, conflicting results have been reported. Both low, and, similar to our study, high cord blood 25(OH)D concentrations have been associated with IgE sensitization, suggesting more a U-shaped or nonlinear association. ${ }^{19-21}$ Because vitamin D deficiency $(<50 \mathrm{nmol} / \mathrm{L})$ was rare in our cohort, we could not confirm the U-shaped association.

The molecular mechanisms of the immunomodulatory effects of vitamin D are not fully understood. Vitamin D has effects on the innate and adaptive immune response, and for example induces antimicrobial peptide production, and modulates T-cell, dendritic cell, and B-cell functions. ${ }^{22}$ In relation to allergy, vitamin $\mathrm{D}$ may be important in the maintenance of type $1 \mathrm{~T}$ helper cell-type $2 \mathrm{~T}$ helper cell balance, and by modulating regulatory $\mathrm{T}$ cells, which are essential in development of immune tolerance. ${ }^{23}$ Interestingly, 2 studies reported a correlation between high cord blood 25(OH)D levels and low numbers of cord blood regulatory $\mathrm{T}$ cells, providing a biological explanation for how high $25(\mathrm{OH}) \mathrm{D}$ levels could increase the risk for allergic sensitization., ${ }^{24}$ Furthermore, the response to vitamin D supplementation may differ between individuals owing to genetic and epigenetic factors. ${ }^{25}$ 
The main strength of our study is the setting: a large, randomized, controlled trial with good adherence to the study protocol. ${ }^{12}$ We measured $25(\mathrm{OH}) \mathrm{D}$ concentrations repeatedly, and allergy outcomes included both clinical and laboratory data. As a limitation, we acknowledge the study to be a secondary analysis of a randomized trial with the sample size not computed for the allergy outcomes. Some of the observed findings could have arisen by chance owing to the multiple comparisons performed. The initial trial length was for 24 months, but unfortunately we were able to measure IgE levels only at the 12 months of follow-up. However, food sensitization prevalence is highest at 12 months of age and may identify children at risk for subsequent allergic disease. In addition, bronchiolitis and wheezing in infancy may serve as early predictors of asthma justifying the selected time-point for outcome evaluation. ${ }^{26,27}$ Our data on clinical allergic diseases were based on parental report, which may have led to bias. At 12 months, the prevalence of food allergies in our study was similar to that of the general population, whereas, for example, wheezing was most likely underreported by parents. ${ }^{28,29}$ However, by measurement of specific IgE levels from a large sample of healthy infants, we were able to obtain unbiased data on allergic sensitization. Furthermore, it is likely that the reporting error would be similar in both intervention groups. Our study lacked vitamin $\mathrm{D}$-deficient infants, which is most likely the result of current health policies in Finland, that is, the recommendation of daily $10 \mu \mathrm{g}$ vitamin $\mathrm{D}$ supplementation to all pregnant women and fortification of food products with vitamin D. ${ }^{30}$ Still, the improved vitamin $\mathrm{D}$ status at birth enabled us to detect the positive association of high cord blood $25(\mathrm{OH}) \mathrm{D}$ concentration with allergic sensitization, which emphasizes the need for further studies concerning possible adverse health effects of high $25(\mathrm{OH}) \mathrm{D}$ levels and the optimal vitamin D dosage. ${ }^{31}$

\section{Conclusions}

We observed that, in vitamin D-sufficient infants, higher vitamin D supplementation did not decrease allergic sensitization, allergic diseases, or wheezing during the first year of life. However, the risk for allergic sensitization was higher in infants with high cord blood $25(\mathrm{OH}) \mathrm{D}$ concentration, suggesting that high vitamin $\mathrm{D}$ levels at birth may modify the immune response related to allergy development. However, the connection of vitamin D and allergy is complex and requires further studies. Because allergic diseases manifest more clearly in later childhood, long-term follow-up of the study cohort is essential.

We thank all the participants in the VIDI study. Also, we thank research nurses Sirpa Nolvi, Rhea Paajanen, Nea Boman, Päivi Turunen, student Aleksi Kukkonen, and laboratory technician Sari Lindén for the help in data collection and laboratory analyses. The midwives and laboratory staff at the Kätilöopisto Helsinki Maternity Hospital and Laboratory of Helsinki University Hospital are acknowledged for their valuable work, and Orion Pharmaceuticals for providing the vitamin D supplements for the study.

Submitted for publication Nov 1, 2018; last revision received Feb 5, 2019; accepted Feb 12, 2019.

Reprints requests: Jenni Rosendahl, MD, Children's Hospital, Pediatric Research Center, University of Helsinki and Helsinki University Hospital, PO Box 705, FIN-00029 HUS, Helsinki, Finland. E-mail: jenni.rosendahl@helsinki.fi

\section{References}

1. Chiu CY, Huang SY, Peng YC, Tsai MH, Hua MC, Yao TC, et al. Maternal vitamin D levels are inversely related to allergic sensitization and atopic diseases in early childhood. Pediatr Allergy Immunol 2015;26:337-43.

2. Weisse K, Winkler S, Hirche F, Herberth G, Hinz D, Bauer M, et al. Maternal and newborn vitamin D status and its impact on food allergy development in the German LINA cohort study. Allergy 2013;68:220-8.

3. Chiu CY, Su KW, Tsai MH, Hua MC, Liao SL, Lai SH, et al. Longitudinal vitamin $\mathrm{D}$ deficiency is inversely related to mite sensitization in early childhood. Pediatr Allergy Immunol 2018;29:254-9.

4. Baïz N, Dargent-Molina P, Wark JD, Souberbielle J, Annesi-Maesano I. Cord serum 25-hydroxyvitamin D and risk of early childhood transient wheezing and atopic dermatitis. J Allergy Clin Immunol 2014;133:14753.

5. Hollams EM, Teo SM, Kusel M, Holt BJ, Holt KE, Inouye M, et al. Vitamin D over the first decade and susceptibility to childhood allergy and asthma. J Allergy Clin Immunol 2017;139:472-81.e9.

6. Morales E, Romieu I, Guerra S, Ballester F, Rebagliato M, Vioque J, et al. Maternal vitamin D status in pregnancy and risk of lower respiratory tract infections, wheezing, and asthma in offspring. Epidemiology 2012;23:64-71.

7. Goldring ST, Griffiths CJ, Martineau AR, Robinson S, Yu C, Poulton S, et al. Prenatal vitamin d supplementation and child respiratory health: a randomised controlled trial. PLoS One 2013;8:e66627.

8. Chawes BL, Bonnelykke K, Stokholm J, Vissing NH, Bjarnadottir E, Schoos AM, et al. Effect of vitamin D3 supplementation during pregnancy on risk of persistent wheeze in the offspring: a randomized clinical trial. JAMA 2016;315:353-61.

9. Litonjua AA, Carey VJ, Laranjo N, Harshfield BJ, McElrath TF, O'Connor GT, et al. Effect of prenatal supplementation with vitamin $\mathrm{d}$ on asthma or recurrent wheezing in offspring by age 3 years: the VDAART randomized clinical trial. JAMA 2016;315:362-70.

10. Yepes-Nunez JJ, Brozek JL, Fiocchi A, Pawankar R, Cuello-Garcia C, Zhang $\mathrm{Y}$, et al. Vitamin D supplementation in primary allergy prevention: systematic review of randomized and non-randomized studies. Allergy 2018;73:37-49.

11. Norizoe C, Akiyama N, Segawa T, Tachimoto H, Mezawa H, Ida H, et al. Increased food allergy and vitamin D: randomized, double-blind, placebo-controlled trial. Pediatr Int 2014;56:6-12.

12. Rosendahl J, Valkama S, Holmlund-Suila E, Enlund-Cerullo M, Hautaalus $\mathrm{H}$, Helve $\mathrm{O}$, et al. Effect of higher vs standard dosage of vitamin D supplementation on bone strength and infection in healthy infants - a randomized clinical trial. JAMA Pediatr 2018;172:646-54.

13. Helve O, Viljakainen H, Holmlund-Suila E, Rosendahl J, Hauta-Alus H, Enlund-Cerullo M, et al. Towards evidence-based vitamin D supplementation in infants: Vitamin D Intervention in Infants (VIDI) - study design and methods of a randomised controlled double-blinded intervention study. BMC Pediatr 2017;17:91.

14. Nwaru BI, Lumia M, Kaila M, Luukkainen P, Tapanainen H, Erkkola M, et al. Validation of the Finnish ISAAC questionnaire on asthma against anti-asthmatic medication reimbursement database in 5-year-old children. Clin Respir J 2011;5:211-8.

15. Wolsk HM, Chawes BL, Litonjua AA, Hollis BW, Waage J, Stokholm J, et al. Prenatal vitamin D supplementation reduces risk of asthma/recurrent wheeze in early childhood: a combined analysis of two randomized controlled trials. PLoS One 2017;12:e0186657. 
16. Chen L, Wilson R, Bennett E, Zosky GR. Identification of vitamin D sensitive pathways during lung development. Respir Res 2016;17:47.

17. Zosky GR, Berry LJ, Elliot JG, James AL, Gorman S, Hart PH. Vitamin D deficiency causes deficits in lung function and alters lung structure. Am J Respir Crit Care Med 2011;183:1336-43.

18. Hypponen E, Sovio U, Wjst M, Patel S, Pekkanen J, Hartikainen AL, et al. Infant vitamin d supplementation and allergic conditions in adulthood: northern Finland birth cohort 1966. Ann N Y Acad Sci 2004;1037:84-95.

19. Rothers J, Wright AL, Stern DA, Halonen M, Camargo CA Jr. Cord blood 25-hydroxyvitamin D levels are associated with aeroallergen sensitization in children from Tucson, Arizona. J Allergy Clin Immunol 2011;128:1093-9.e1-5.

20. Hypponen E, Berry DJ, Wjst M, Power C. Serum 25-hydroxyvitamin D and IgE - a significant but nonlinear relationship. Allergy 2009;64:613-20.

21. Savilahti EM, Makitie O, Kukkonen AK, Andersson S, Viljakainen H, Savilahti E, et al. Serum 25-hydroxyvitamin D in early childhood is nonlinearly associated with allergy. Int Arch Allergy Immunol 2016;170:141-8.

22. Hewison M. An update on vitamin D and human immunity. Clin Endocrinol (Oxf) 2012;76:315-25.

23. Mirzakhani H, Al-Garawi A, Weiss ST, Litonjua AA. Vitamin D and the development of allergic disease: how important is it? Clin Exp Allergy 2015;45:114-25.

24. Chi A, Wildfire J, McLoughlin R, Wood RA, Bloomberg GR, Kattan M, et al. Umbilical cord plasma 25-hydroxyvitamin D concentration and immune function at birth: the Urban Environment and Childhood Asthma study. Clin Exp Allergy 2011;41:842-50.

25. Carlberg C, Haq A. The concept of the personal vitamin D response index. J Steroid Biochem Mol Biol 2018;175:12-7.

26. Alduraywish SA, Lodge CJ, Vicendese D, Lowe AJ, Erbas B, Matheson MC, et al. Sensitization to milk, egg and peanut from birth to 18 years: a longitudinal study of a cohort at risk of allergic disease. Pediatr Allergy Immunol 2016;27:83-91.

27. Beigelman A, Bacharier LB. Early-life respiratory infections and asthma development: role in disease pathogenesis and potential targets for disease prevention. Curr Opin Allergy Clin Immunol 2016;16:172-8.

28. Venkataraman D, Erlewyn-Lajeunesse M, Kurukulaaratchy RJ, Potter S, Roberts G, Matthews S, et al. Prevalence and longitudinal trends of food allergy during childhood and adolescence: results of the Isle of Wight Birth Cohort study. Clin Exp Allergy 2018;48:394-402.

29. Jurca M, Pescatore AM, Goutaki M, Spycher BD, Beardsmore CS, Kuehni CE. Age-related changes in childhood wheezing characteristics: a whole population study. Pediatr Pulmonol 2017;52:1250-9.

30. Hauta-Alus HH, Holmlund-Suila EM, Rita HJ, Enlund-Cerullo M, Rosendahl J, Valkama SM, et al. Season, dietary factors, and physical activity modify 25-hydroxyvitamin D concentration during pregnancy. Eur J Nutr 2017;57:1369.

31. Morgan DJ, Dhruva SS, Coon ER, Wright SM, Korenstein D. 2018 Update on medical overuse. JAMA Intern Med 2019;179:240-6. 


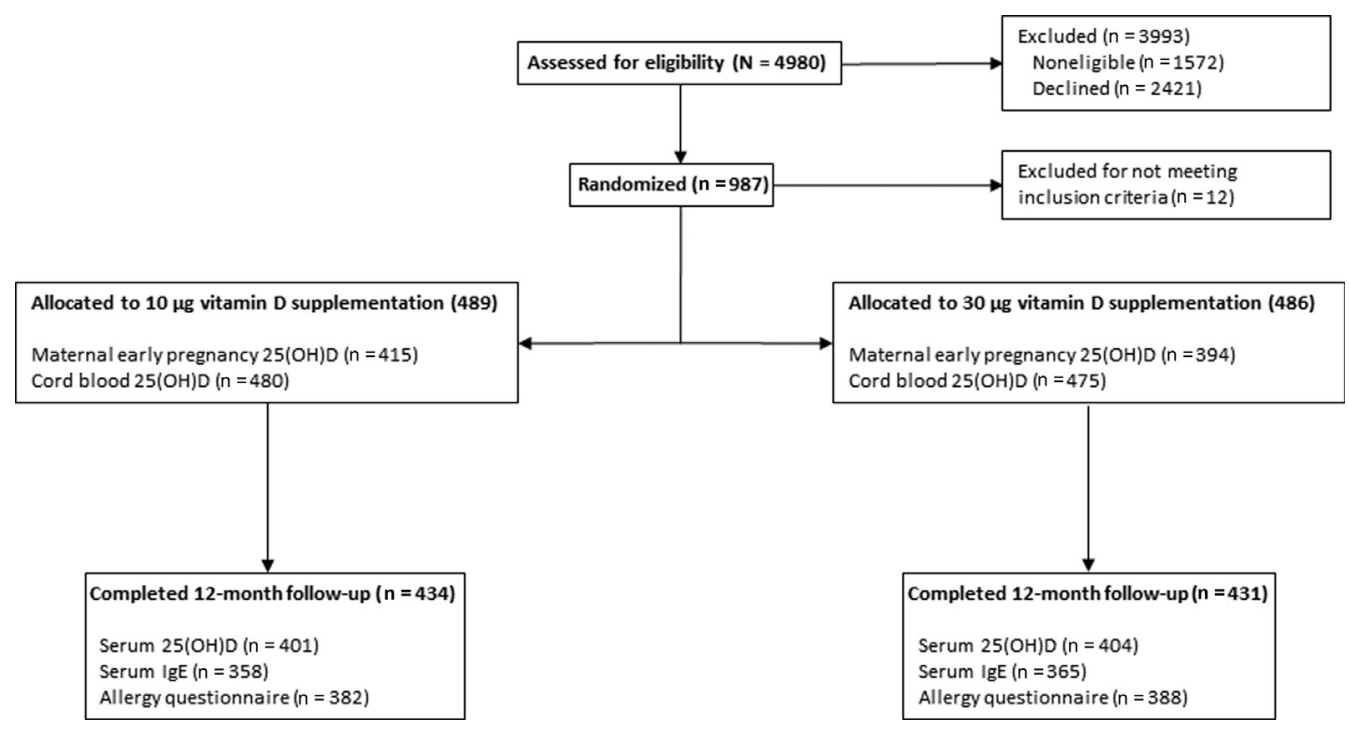

Figure. Flow chart of the study enrollment, allocation, and follow-up. 